This is a peer-reviewed, accepted author manuscript of the following research article: Adams, P., \& Mann, K. (2020). Teacher professional learning and professional update in Scotland. Education https://doi.org/10.1080/03004279.2020.1751228

\title{
Teacher Professional Learning and Professional Update in Scotland
}

\section{Dr Paul Adams}

School of Education

Faculty of Humanities and Social Sciences

University of Strathclyde

St James' Road

Glasgow

G4 OLT

Email: paul.adams@strath.ac.uk

Tel: 01414448078

\section{Kirsten Mann}

The Nurture Group Network

Abbey Mill Business Centre

Mile End Mill

12 Seedhill Road

Paisley

PA1 1JS

Email: kirsten@nurturegroups.org

Tel: 01412800524 


\title{
Teacher professional learning and Professional Update in Scotland
}

\begin{abstract}
The research here presented discusses teacher professional learning ( $P L)$ policy in Scotland and in particular the recently introduced Professional Update (PU). From 2001, there have been significant policy reforms in relation to PL in Scotland including a new Standard for Career Long Professional Learning (SCLPL) and PU. The research identified how PU has been located by a small number of primary teachers. A qualitative research design was employed and seven teachers were interviewed for their views on PL and PU. None of the teachers explicitly described engaging with SCLPL and associated procedures. PU was considered to be bureaucratic with little to do with learning. For the participants, PL appeared to be located in, and dependent upon, school and local authority contexts. However, accountability for learning seems to rest with individual teachers through the mechanisms of PU. Recommendations for further study are provided.
\end{abstract}




\section{Introduction}

Globalisation has increasingly led to comparisons between education systems across the world and their role in developing economies (King, 2014). Some countries, for example England and the United States, have related this to teacher pay, while others, for example the Republic of Ireland, have increased focus on selfevaluation as validated by external agencies (Sugrue, 2011; Grek et al, 2009). Ireland's focus on teacher learning centres on ways in which professionals working in schools might embed reflection and research with their professional practice and is detailed in a framework of standards (The Teaching Council of Ireland, 2016). Similarly New Zealand has a Code of Professional Responsibility and Standards for the Teaching Profession (Education Council New Zealand, 2017) underpinned by indigenous values. Here, professional learning is one focus for the work of teachers.

It is notable that national policies across the globe have sought to formalise teacher accountability in various forms. Linked to this is a growing body of research around two connected key areas: the role of the individual teacher in making a significant impact on pupil progress; and, professional learning that enables teachers to achieve positive outcomes for pupils (Timperley, 2008; OECD, 2005). Increasingly, there are arguments in favour of new designs for teacher learning such as: teachers as learners engaged in practical enquiry; collaboration with colleagues; mentoring; and, peer support and coaching (Timperley, 2008; Sugrue 2011; Coe, Aloisi, Higgins \& Major, 2014). In Scotland, perceived deficits in pupil outcomes in comparison to other countries and between pupils from different socio-economic backgrounds have driven recent reforms (Scottish Government, 2017) and key policy changes have sought to influence teacher learning. In 2010/11 teacher experiences of continuing professional development (CPD) and associated structures were reviewed, resulting in significant policy changes (Donaldson, 2011). In Scotland, CPD became professional learning and, more recently, career long professional learning (CLPL). For the purposes of this paper, professional learning $(P L)$ refers to all activities considered as developing of teacher learning. Nevertheless, as noted here, internationally, terms such as CPD and teacher development are still widely used.

Importantly, policy change in Scotland has received much attention. However, little is known about the impact on individual teachers and the implications of further 
change. The recent National Improvement Framework (Scottish Government, 2019) cites teacher professionalism as a key driver to close the attainment gap between the most economically deprived pupils and the general population.

This paper examines Scottish PL policy. First the paper discusses, briefly, the nature of $\mathrm{PL}$ in relation to previous ideas of CPD. Second the Scottish context for recent policy developments is outlined. Following this is an examination of the methodology and methods used in the small-scale study. The paper then continues with a presentation of key aspects of the data gathered. The paper then examines the implications for the development of Scottish policy before, finally, concluding with an outline of possible lines for further research.

\section{Professional Learning}

While much of the research in teacher PL has focused on the activities with which teachers engage, there has been relatively less research carried out in relation to the processes that led them to their learning and the extent to which they had increased levels of agency and choice (Rhaman, Hoban and Nielsen, 2014). The literature suggests that traditional views of teacher learning are sequential and deterministic, that is, there is a direct causal relationship between teacher learning, beliefs and practice changes (Guskey 2002; Clarke \& Hollingsworth, 2002; Desimone, 2009). Associated models such as cascading present neat views of the process but do not fully explain why PL can be (in)effective. A lack of relevance to teachers' own school/class context coupled with little time available for discussion and sharing or to try out new learning often means that such training has little impact (Rhaman et al., 2014). At its heart, most PL, in the guise of Continuing Professional Development (CPD) was delivered in a traditional, didactic manner separate from work experiences and often symptomatic of the theory/practice divide. Calls for a more interactive form of CPD have emerged, whereby professional development is schoolbased and embedded in teachers' everyday work.

At its heart, CPD seeks to ensure the ongoing competence of workers to discharge their duties and obligations. However, as Harland and Kinder (1997) note, matters such as values have often been left wanting in such endeavours, or have been 
elided altogether. Indeed, Watson and Fox (2015 citing Short, 1984) note that competence and competency have become conflated, eliding being and doing.

It is this semantic sleight of hand that enables competence standards to serve as instruments both to construct professional subjectivities and to measure performance. (Watson and Fox, 2015: 133)

Mechanisms for (re)accrediting professional competence are not confined to teaching. Notably, professions such as health have introduced systems which link appraisal to the maintenance of professional registration (Watson and Fox, 2015). Subsequently, professional learning has been cited as a mechanism for ensuring the ongoing development of the teaching learning relationship. As Timperley notes:

Professional learning experiences that focus on the links between particular teaching activities and valued student outcomes are associated with positive impacts on those outcomes. (2008: 8)

A notable development in the journey towards PL is the shift from development to learning. Writers such as Clarke and Hollingsworth (2002) and Opfer \& Pedder (2011) argue that change occurs within different domains of reflection and enactment and that these occur in systems such as school culture, leadership and local contexts. These views contrast squarely with traditional ideas of CPD, the implication being that a traditional, sequential, deterministic view may lead to unsatisfactory learning experiences if, in reality, the conditions needed for learning to be effective are more complex. This is foregrounded clearly by the Teaching Council of Ireland (2011) where professional learning is understood as a continuum. Such orientations locate PL as a career long progressive activity that helps to develop capabilities and capacities.

Accordingly, there are implications for measuring and evaluating the impact of PL. Whilst a simple deterministic approach may well facilitate less convoluted evaluation methods and methodologies, it is clear that the complex nature of PL does not lend itself to simplistic measures. Some, such as King (2014), and Earley and Porritt (2013) orient PL as intended outcomes identified at the start of the process and measurable through, for example, pupil work, policy documents or improved systems. However, identifying PL as having occurred when predefined outcomes 
have been met is still deterministic and may miss subtle nuances. A simple relationship between learning and practice is somewhat unsustainable when the nature of both is considered in depth. There is evidence that schools have difficulties measuring the impact of PL even within given structures or frameworks (Coldwel \& Simkins, 2011; Pedder, Storey \& Opfer, 2008). It may be that presenting a narrow perspective of $\mathrm{PL}$ that is formal, sequential and deterministic, and where outcomes are measurable in advance does not reflect the complexity of the PL process.

Whilst the above considerations might be part of official provision, it is fair to say that not all PL is formal and planned. Such PL may run in tandem with educational development that is broadly constructivist in line (Author, 2006). Advocates of formal and informal PL recognition (cf. Postholm, 2012; Cordingley, Bell, Rundell \& Evans, 2005) argue that existing knowledge needs to be developed through interaction and dialogue with more experienced others or specialist staff. This marks a move from dependency to autonomy (Glaser cited in Alexander, 2010).

\section{The Scottish Policy Context}

The belief that PL is linked to both personal aspects such as values and beliefs, and occupational domains such as professional relevance, is of particular importance within the Scottish context. Local Authorities (LAs) are key drivers in directing school priorities (Ledingham, 2013) and thus activity at a local level is crucial.

Since 2001, in Scotland, there have been a number of policies focusing on teacher CPD and PL. The publication and implementation of $A$ Teaching Profession for the 21st Century (known as the McCrone Report) (Scottish Executive, 2001) required teachers to undertake 35 hours CPD per year and to keep a record to be discussed at annual Professional Review and Development (PRD) meetings. This raising of the profile of PL was followed by significant foci on high quality CPD experiences for all teachers through the launch of a new suite of standards. This included Provisional Standards for those in Initial Teacher Education (ITE); the Standard for Full Registration, a benchmark for those undertaking their induction year; the Standard for Headship; and, the Standard for Chartered Teachers. Teaching Scotland's Future (Donaldson, 2011) took up the mantle of career-long PL. Here, traditional forms of 
CPD, such as one-day courses with cascade methodology, were eschewed in favour of an emphasis on collaborative learning and practitioner enquiry (cf. OECD, 2005).

Certainly, from 2011 flexibility was seen as the cornerstone of PL provision and was endorsed by the Scottish Government (Scottish Government, 2011). Localism, collaboration and a focus on school and individual reflection and evaluation were key features and were captured in the subsequent iteration of Professional Standards (GTCS, 2012). Controversially, the Chartered Teacher Scheme was discontinued in 2011 and was superseded by the Standard for Career Long Professional Learning (SCLPL). Notably this,

[c]odifies the processes of professional learning and shifts the focus for teachers from a 'once and for all' attainment of a set of competences to an ongoing engagement in the processes of professional learning.

Underpinning SCLPL is practitioner enquiry. Wording implies that teachers: are autonomous; able to shape their professional learning experiences to '...create knowledge to enhance, progress and lead the learning experiences of all their learners and work collaboratively with colleagues' (GTCS, 2012b). Forde et al. (2016) contend that in order to use SCLPL to support planning and reflection on professional learning, teachers need to develop appropriate skills. They argue that this 'requires on the part of teachers a deep understanding of the context of their practice and an awareness of themselves as practitioners and learners working in this context' (31).

It can be surmised then, that since 2011, in Scotland, there has been a shift in orientation from a one-stop-shop CPD approach whereby standards are reached and assumed to be maintained, to a more dynamic set of requirements for ongoing PL. Indeed, Donaldson called for a 'Standard for Active Registration' which should be 'challenging and aspirational, fully embracing enhanced professionalism for teachers in Scotland' (Donaldson, 2001: 69). This served to be the catalyst for the introduction of a career-wide reaccreditation scheme known as Professional Update (PU) in 2014. 
PU has two functions. First, it is a mechanism for ensuring that all teachers receive annual PRD meetings with their line manager. Additionally, it requires engagement in PL activities that impact on thinking, professional actions, colleagues and/or pupils. The GTCS state, evidence of impact

...should help you develop knowledge and understanding of practice and pupils' learning [and] be about a genuine reflection and analysis of your thinking, practice and professional actions' (GTCS, 2014a).

Second, it serves as a reaccreditation process. Every five years, PRD takes on the function of a PU discussion. Line managers 'sign-off' the PU and teachers retain GTCS registration. This links the process of PU to annual PRD: teachers meet with line managers to reflect on and evaluate the impact of their professional learning and set targets for the following year. Although every teacher is entitled to PRD, evidence indicates that the quality and regularity of PRDs varies across the country (Humes, 2014).

However, at the time of Hume's research little was known about the impact of PU. Despite this, Watson and Fox (2015) found little concern from teachers involved in the PU pilot about the potential differences in outcomes of the yearly PRD meeting and five yearly $\mathrm{PU}$, although there was some disquiet that the latter might become another bureaucratic exercise (Hepburn, 2015). To allay such fears, GTCS emphasises that $\mathrm{PU}$ concerns itself with improvements to practice, rather than proving competence (Watson and Fox, 2015). Notably, Watson and Fox (2015: 140) found that line managers did not associate PU with measuring competence. Indeed, in addition to the GTCS framework for teacher competence (2012a), Local Authorities (LAs) and other employers have their own procedures to deal with competence matters.

However, the aims of PU undoubtedly connect to teacher quality. Problematically, the GTCS makes the different use of standards clear, for example, describing the Standard for Full Registration as the 'benchmark for professional competence' (GTCS, 2014a). Presumably, after a successful probationary year, the assumption is that teachers have met and will maintain this benchmark as the other standards 
should be used for those who have 'achieved' the standard for full registration as a reference for self-evaluation and professional learning (GTCS, 2014a). Undeniably, there has recently been a shift to aligning PU to issues of competence. Given the international focus on the connection between teacher quality and impact on pupils, PU proposes to 'maintain and improve teacher quality' and makes a strong connection to professional learning as a vehicle for achieving this (GTCS, 2014a). Importantly, the obligation for all teachers to participate in PU, in order to maintain registration with the GTCS connects with accountability issues. There appears, then, a tacit acceptance that PU is about ensuring school systems and processes support teachers to develop and improve. Indeed, challenges made within the PU pilot projects were around issues of time, workload and ease of use rather than principles (GTCS, 2015). The only concerns came from unions, but their eventual acquiescence meant that teachers were to accept this process as part of their professional obligation.

Further, GTCS support materials (GTCS, 2014b) acknowledge the importance of reflection; there is specific reference to 'genuine reflection' and 'critical reflection'. Such ideas have been in teacher education for many years and definitions such as reflection in action and reflection on action (Schon, 1983) are arguably familiar. However, there is a lack of clarity over what reflection means in practice (Collin, Karsenti \& Komis, 2013; Eraut, 1994; Hatton \& Smith, 1995). Whilst the GTCS invites teachers to reflect against the Professional Standards and to consider questions such as, 'How do I critically reflect on my own assumptions, beliefs and values', 'Who am I as a teacher' and, 'What has influenced me, what sustains me?', there could be potential tensions between reflection and evaluating impact. Accepting that PL nests within a complex system, there could be tensions between school and individual priorities (Day \& Sachs, 2004). Moreover, if the issue of evidencing learning becomes the overriding factor for PU and hence proving, not improving, there may be a danger it inhibits what teachers report or, worse, that professional learning activities in which they choose to engage are constrained. As Tuinamuana (2011) argues, where policies offer the promise of devolved responsibility, resulting in more ownership and a sense of empowerment, the outcomes can end up being counter-productive as additional forms of monitoring stifle creativity, innovation and collaboration. Consequently, teachers (and schools) 
may end up undertaking activities that can be easily evidenced rather than genuine learning experiences.

It would appear then, in Scotland, that historic views of professional learning as a linear, deterministic process are being rejected in favour of more complex models that take account of a number of factors affecting learning effectiveness. Here, the increasing emphasis placed on individual teacher responsibility and accountability reflects PL policies: but there are questions to ask, one of which is, "what are the tensions between PL policy and practice?'

\section{Research Design}

This research considers how teachers make sense of PL policy and practice, and in part, this sense making occurred through the interviews conducted. A constructivist stance was taken for the research: an acknowledgement of the complexity of the social, where people make meaning from and contribute to the world around them (Robson, 2002). The research design is qualitative and is concerned with individual teacher 'stories' of professional learning. Here, Punch (2014) states

For the qualitative researcher, the "truth" about human behaviour is not independent of context; it is not context free. Therefore, it is important for the qualitative researcher to be able to convey the full picture. (p.161)

The relationship between context and research is multi-dimensional: for participants there is a cultural, policy context. LA policies and school cultures are influencing factors along with participant histories. When seeking fidelity within the research it was important to recognise interaction between these contexts. In this way, the research sought to uncover not only what participants did, but what they thought within the surrounding context.

Survey questionnaires were discounted due to the fact that more open ended questions would reduce speed of completion and analysis and increase the risk of a lower number of responses. Additionally, there would be little opportunity to clarify or explore issues in relation to individual experience and perception. Focus groups 
were also discounted due to the lack of data they would provide regarding individual experiences, due to the interactional nature of positional construction.

Data were gathered via semi-structured interviews. Cohen, Manion and Morrison (2007) contend that in interviews knowledge is developed between the interactions of two or more people on an area of mutual interest. Interviews can be more flexible than other data gathering methods as adjustments can be made and responses can be followed up or clarified. Semi-structured approaches allow for general areas to be addressed but maintain flexibility to explore aspects that may be of interest to the interviewee or allow the interviewer to follow up or seek clarification.

Although interviews can be open to bias due to an "asymmetry of power" (Sheurich, 1995) as qualitative researchers taking an emotionalist stance are concerned with the authenticity of accounts of subjective experiences, Silverman (2006: 123) points out,

The key here is to obtain rapport with respondents and to avoid manipulating them. So, while positivists regard departure from an interview schedule as a possible source of bias, emotionalists may actually encourage it.

For both practical and methodological reasons the research deployed a combination of convenience and purposive sampling. Convenience, via the utilisation of an existing professional development network (this was the most time efficient and practical way of recruiting participants) from contacts the researcher made whilst leading Nurture Group training; and, purposive in that selection criteria were such that teachers should have more than a 50\% teaching commitment. Participants needed to have a considerably large portion of their working week aligned with 'classroom' type activities so that the views of non-managers were gleaned. Additionally, the view that class teachers' practice has a direct influence on pupil achievement informed this decision. In addition, the original sample were asked to share requests for participation with colleagues.

Contact was made with fifteen teachers via the pre-existing Nurture Group email list. These teachers were asked if they would consider taking part in a semi-structured 
interview on CLPL and PU. Thirteen responded with two further teachers recruited via snowball sampling. Arrangements were made to meet teachers in their place of work at a convenient time. Two pilot interviews were carried out in order to test the practical aspects of interviewing, such as recording and transcription, and to test the quality of questions. Minor question modification followed the pilot and this data was not used in the project. Seven teachers were interviewed for the project; some who had originally agreed were unable to do so because of various unforeseen circumstances. The questions asked about professional experience, including PL, personal experience of PU and PRD and professional standards.

The teachers ranged in experience with three having between one and three years teaching experience and 4 having taught for eight or more years. All participants were primary teachers. This was not a sample criterion; rather, of those contacted only primary teachers agreed and were able to participate. The teachers worked in a range of Scottish LAs (7 in total) and a range of school contexts from one small, rural school to urban schools with between 150 and 300 pupils. Interviews were audio recorded then sent to a transcription service. Participants agreed to the transcription process prior to interview and written consent was obtained for the research. All transcriptions were anonymous and under the terms of agreement with the transcription service, all data was deleted two weeks after completion. Ethics approval was granted by [name] University.

Thematic analysis was used to analyse the data. Braun and Clarke (2006) describe this as searching across a data set to find repeated patterns and meanings. Categories are identified which may already exist or may emerge from the data (Miles \& Huberman, 1994).

The data was coded manually with the process of analysis drawing on the work of Braun and Clarke (2006: 87) who offer a detailed step by step method of thematic analysis that includes: familiarising oneself with the data; generating initial codes; searching for themes; reviewing themes; defining and naming themes; and producing a report. Richards (2009: 83) refers to this as working up from the data describing it as 
...a process of coding the data without trying to fit it into a pre-existing coding frame, or the researcher's analytic preconceptions. In this sense, this form of thematic analysis is datadriven.

Each transcript was coded three times. First, notes were taken on the transcript, then a table was set up to code more specifically. This was then checked to reduce duplicate coding. The seven sets of coded extracts were then sorted manually into recurring categories. Patterns were noted in a variety of hierarchical diagrams reflecting emerging themes and sub themes. Each theme was summarised in diagram form and then related back to the original research questions.

\section{Results}

Responses can be divided into two, broad areas: teachers' experiences of professional learning and impact on practice; and, teachers' experiences of enacting policies related to professional learning. Here, only the latter is discussed.

Teachers were asked about their experiences of policy related to PL, PRD, PU and professional standards. For PRD, the results were graphically represented as in figure 1. 


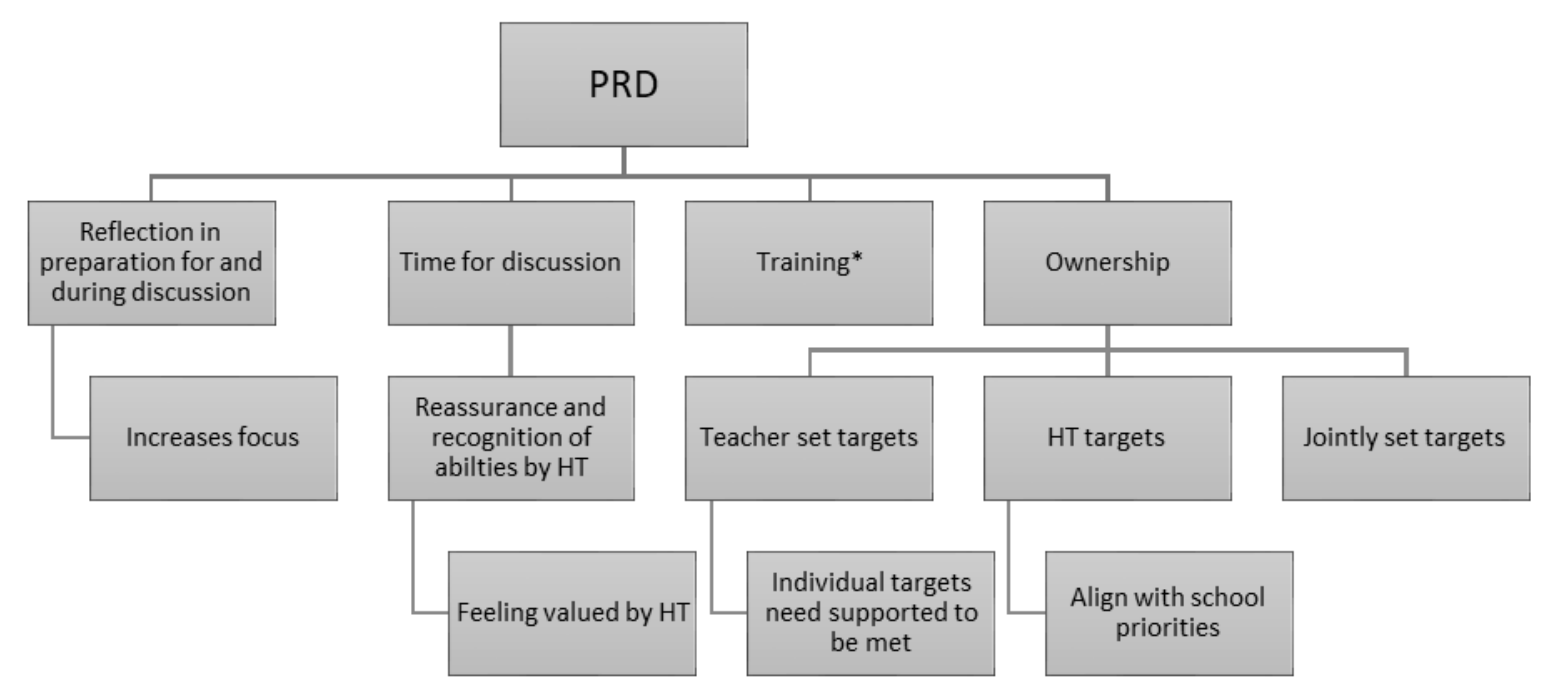

* Two most recently qualified teachers expressed a lack of understanding

Figure 1: Interviewees' views of Professional Review and Development (PRD)

Some had a positive experience of PRD: they felt that time had been taken for an in depth discussion and that they were encouraged to take ownership. For example, interviewee 7 describes different experiences of PRD discussions:

I'd had a PRD before I went on maternity with my previous head teacher, but it was very - we were given a form to fill in and it was very basic in comparison, whereas this one was a lot more in depth, a lot more about what I wanted to say, what I wanted to do, what I wanted to take forward, as opposed to what I thought I should be saying. This was what I wanted to say.

For some, discussion with their line manager was valued; they felt they had a sense of process ownership. However, for some, this sense of ownership was less important; rather, direction and a judgement of strengths and needs by their line manager was considered more helpful:

I've actually got one on Monday, coming up and we've been told the same things to ask, what you think you're doing well, what you would like to work on and in terms of any CPD opportunities, what would you like to do or what are 
you going to be doing to develop that. So, that's the kind of PRD. But to me, I think a PRD should be well this is what I think you're doing really well. This is how I think you could improve on that, but it's not done like that, it's more just sort of a formal chat and I don't feel it's very personal. (Interviewee 2)

The opportunity to gain external recognition and value for their work from line managers was common among some:

(The PRD discussion) allowed me to realise that I was actually better at a lot of things than what I thought I was and that allowed me to realise that people were recognising the work that I was doing and it was seen as being a better job than I thought it would have been perceived as. So, that was a lovely feeling. (Interviewee 4)

Teachers were asked if their PRD linked with the school improvement plan. All who had experienced regular PRD discussions said that at least some of their targets thus linked. The way this was taken forward differed though: for example, interviewee 1 describes being directed to take responsibilities for developing aspects but had ownership over how she went about this:

Then it tends to be because the development plan ${ }^{1}$ is usually already done it is usually a case of, "Well we are looking for you to be taking these forward". The broad areas and the broader targets are kind of already there. Then we have the dialogue to talk about, "We do that by doing this, this and this".

Interviewee 6 explained that her head teacher encouraged her to set targets that were specific to her job remit:

Obviously I'm kind of new to this school and I did feel that the head teacher was really for me looking for quality out of my training that I'm doing this year rather than quantity, whereas before I've kind of felt I've had to do courses or have a list of things and get through quite a lot. She was great really at

\footnotetext{
1 Schools are required to produce development plans in line with LA priorities and school needs. These form the basis of the direction for the schools work.
} 
saying, "Look, this is going to be your focus." There were two things that she really wanted me to look at...

While there were differences over the way PRD targets were set, many were directed and guided by the focus of the school improvement plan or by the demands of specific job remits.

What was notable, was the relationship between PRD and Professional Standards. This relationship is represented graphically in figure 2 .

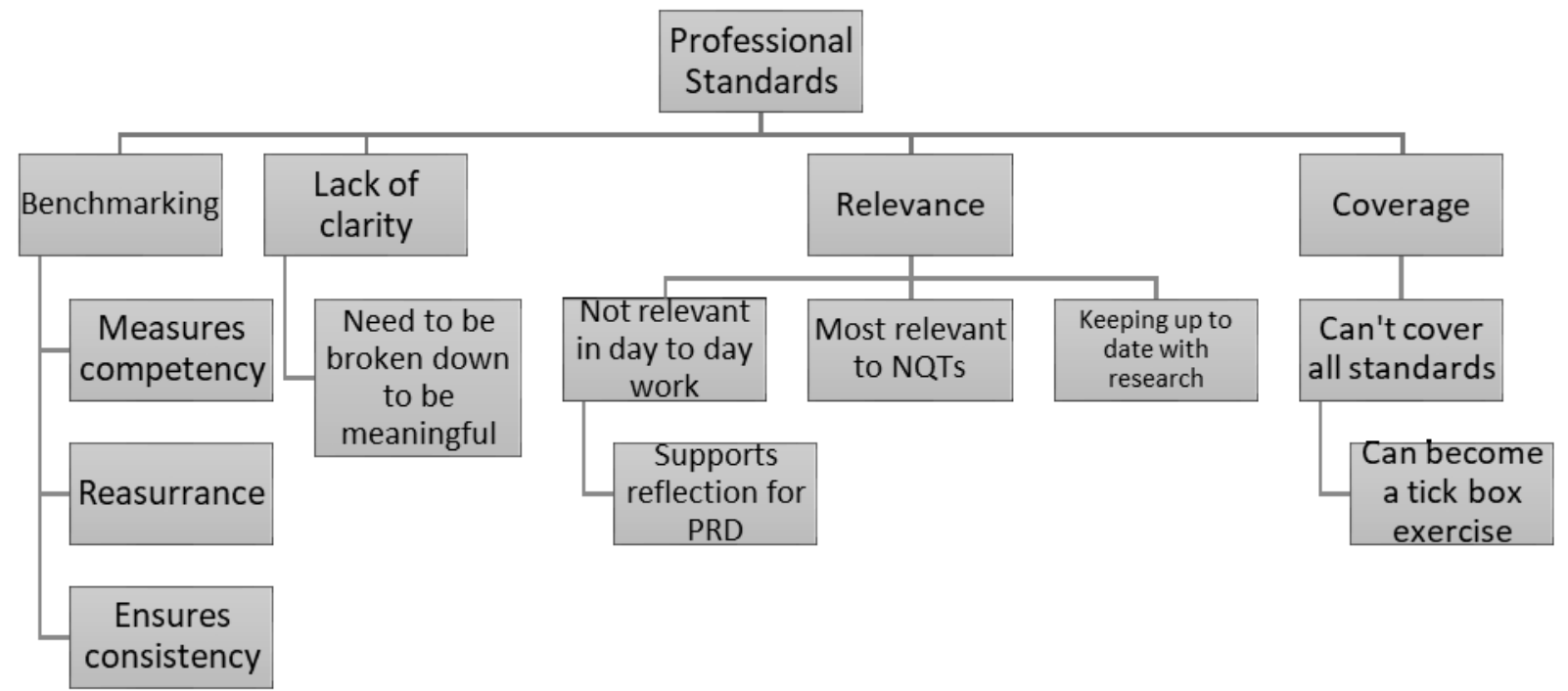

Figure 2: The relationship between PRD and PU and Professional standards

No teacher referenced the Standard for Registration or the SCLPL; rather, they discussed standards in generic terms. Most reported the standards were not relevant in their day-to-day work.

But, to be honest, I don't think they're meaningful for people that have been teaching for quite a long time. I don't know if, if you asked another teacher 
that maybe hadn't had a mentoring role. Or myself, even I hadn't had a mentoring role, would I have looked at them? (Interviewee 1)

Some felt the standards were most relevant to probationary teachers:

But, I think when you qualify as a teacher, I don't think you think about it the same, because as I say, I think you're so ecstatic that you don't have to do it...almost don't have to do it. It's not a thing you really think about an awful lot. (Interviewee 2)

It was very standard focussed last year. That's not translated over into full registration. (Interviewee 5)

Nevertheless, although the teachers felt the standards might not have direct relevance to them, there was a sense that their purpose was to benchmark for competency and provide reassurance and consistency. Engagement with standards occurred in preparation for PRD record keeping, mentoring a probationer teacher, or during the probationary year. In addition, one of the teachers had a system in school whereby classroom observations by the head teacher were carried out against the standards. Standards were also discussed in relation to PU. The process of PU was often discussed in terms of administration and record keeping. Overall, the general theme was that PU was about a system of recording PL; completion by a specific deadline and an administrative task.

Those who had not yet engaged with PU had gleaned information from colleagues. The interviewees' responses in relations to PU are recorded graphically in figure 3. For example:

I'm assuming it's the same as your probation year, so, recording your professional learning and allowing that to be built up as a bank of Professional Learning that you can use, that you've been on and that it's recorded in a way that you can relate back to, if you ever need a wee memory minder. (Interviewee 4) 
Now it came up in my maternity year so I didn't... I sort of escaped it. So I know that it's about the learning log and looking at your CPD and the impact it's had and things like that, but I've not actually been through the process myself. (Interviewee 6)

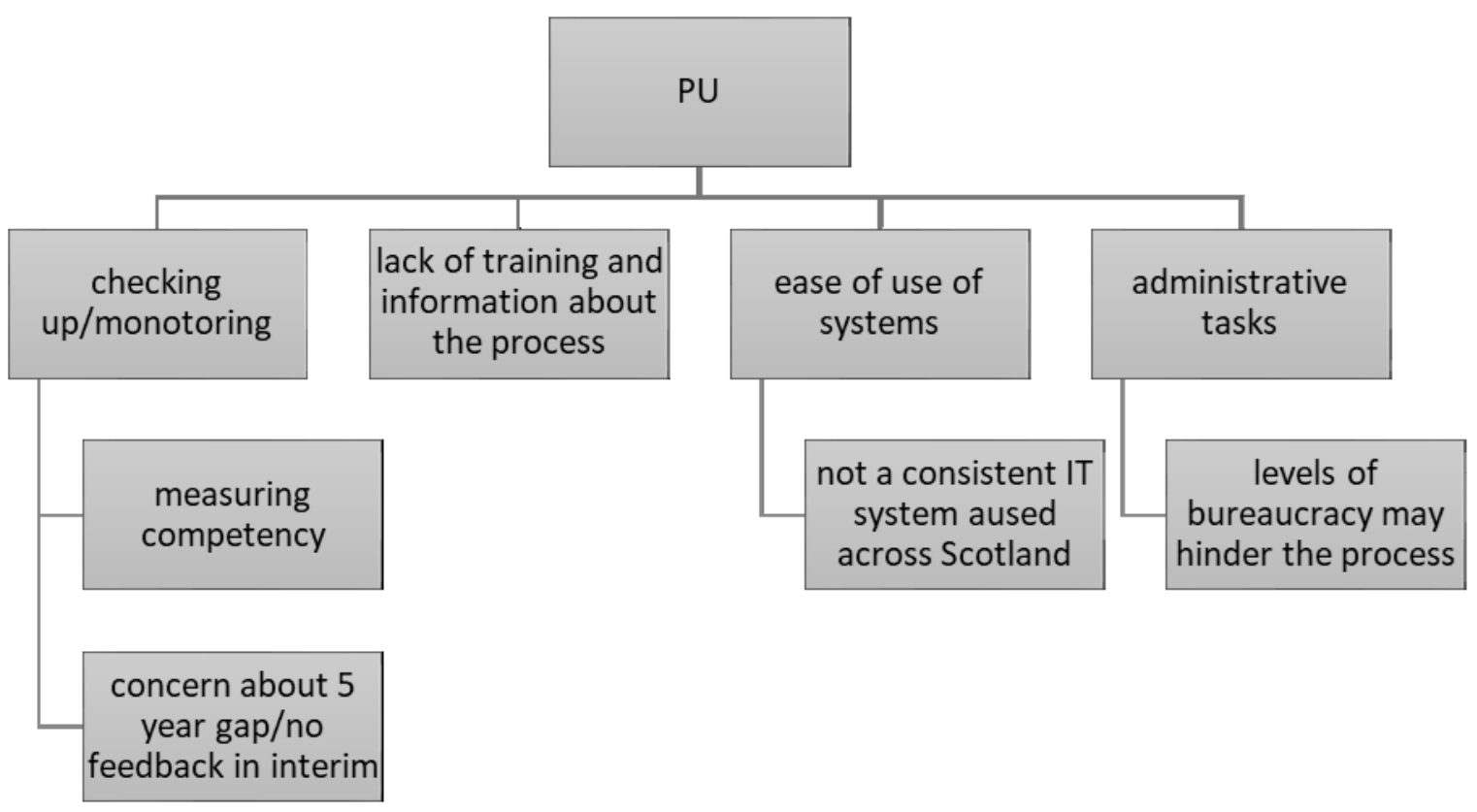

Figure 3: Interviewees' responses concerning Professional Update.

For these teachers, knowledge of PU relates to record keeping against a set of competences, more akin to CPD than PL. For teachers who had engaged with PU the focus of the discussion ranged from the purpose of professional update as a policy to measure and ensure competency, to the ease of use of the IT system supporting the record keeping.

I started keeping my journal a couple of years ago on the website and things. Then last year in the middle of the year about November time with no notice, or if it did I missed it, they totally changed the format for recording your Professional Update. In the time that I hadn't been on it, it had totally changed and totally flummoxed me first time I went back on it. It was that kind of, "Right 
I am just going to come out of that because that is not what I was expecting to see." (Interviewee 1)

I had to have it finished by the end of term. This was probably a couple of days before the end of term. It was horrendous trying to get it together and get it done, so I didn't have a good experience doing it. (Interviewee 7)

But it was easy, it was user friendly, it was focussed enough. There wasn't too much in it that it takes over and takes too much time. I think it's a good process. And it was quite easy to sign it off and you know and that was fine. (Interviewee 3)

For the teachers who had engaged in PU it was the quality of the PRD discussion which was valued. Even for interviewee 7 who described the process of recording as 'horrendous' there was a positive aspect:

I think the valuable process was talking to the head teacher, sitting and having that one-to one meeting with him, that was valuable. Spending the time writing it, wasn't. You don't have the time to do that, but the actual verbal communication, and the time given for that; that was valuable.

Reflection bridged both discussions around competency and the processes around enacting policy. From the data there appeared to be both descriptions of formal structured reflection, for example in preparation for PRD meetings, or reflecting against the professional standards as required for PU. Informal reflection was described as an individual and collaborative practice, often as part of a whole school change approach. As well as the formal processes, there was a sense that reflection was an integral and ongoing part of the teaching job, although for one teacher, the process was enhanced because of $\mathrm{PU}$ and the requirement to reflect against the standards:

They definitely make you reflect more. I would say I was quite reflective on my practice. But I would say I was more so now having been through 
Professional Update and using the standards. Again it is about making sure you have got those breadths of the standards. (Interviewee 1)

\section{Discussion}

Teachers' experiences of national PL policies

Most participants valued discussions with their line managers although expectations of how PRD targets should be formed differed. All indicated some targets were linked to school improvement plans. Reflection against the professional standards occurred in preparation for PRD. Professional Standards were thought to be a benchmark and a mechanism for ensuring consistency but were also thought to be most relevant to teachers in their probationary year. Reflection against the standards also took place during the process of PU: those who had engaged with this viewed it as an administrative task to be completed with little support materials and available information. Reflection was also a prevailing theme both in relation to PL experiences and related policies; informal and formal reflection was described both as an individual and collective activity.

The GTCS has a distinct vision of the role of PU in terms of supporting teacher development needs, self-evaluation and professional learning. Included within the PU policy is an entitlement to supportive PRD; the GTCS recommends that teachers have ownership over the process (GTCS, 2014b). However, participant experience varied depending on the personnel conducting the PRD and, for one teacher at least, there was a different expectation over process ownership: they would have preferred more direction and guidance. This participant was relatively inexperienced. This links with Glaser's (in Alexander, 2010) argument that as teachers become more experienced they move from dependence to autonomy. If this is a common theme for teachers in Scotland, it may be that school leaders will have to become more adept at PRD meetings. It would seem again that teachers are affected individually by a policy that is dependent on other factors, in this case school leaders.

Whilst the teachers valued PRD discussion, whether part of the PU process or not, the role of professional standards was not clear. The teachers in this project did not refer to individual sets of standards, for example the Standard for Career Long Professional Learning (SCLPL): reference was often made in generic terms. 
Participants referred to standards in preparation for a PRD meeting, but some talked of coverage as a 'tick box' exercise. Some felt the standards were most relevant to probationary teachers, possibly because they are required to regularly and explicitly reference these in their record keeping and learning evaluations. For one teacher there was some relief when there was less focus on this in the years that followed probation. The Donaldson Review (2011) found a lack of engagement with professional standards; however, for some in this project Donaldson's vision that PU would address this has yet to be achieved.

The fact that teachers only apparently referenced the Standard for Registration (SFR) is significant. The lack of reference to the SCLPL among experienced teachers perhaps indicates a lack of awareness of the standards or, because of their non-statutory nature, a lack of relevance. In addition, adherence to the SFR may indicate a compliance culture rather than individual agency. Some participants did describe incidences where they were engaging at the level of professional enquiry (GTCS, 2012b), but they required support and trust to be able to do this. It would appear, here at least, that school context, rather than Standards, creates the conditions by which this could happen. Even though Forde et al (2016) suggest that context and awareness are paramount for development against the SCLPL, here teachers gave no indication of having experienced any support to use these standards.

For all those who had set PRD targets at least some aligned with school priorities. Again, this supports the view that processes are nested within the school system in general (Rahman et al. 2014). The only teacher who had not had an opportunity to engage in PRD was one who was employed on a temporary contract. Here, the transition between probationary year and a full time temporary contract at a different school made the action plan set at the end of the probationary year (essentially the first PRD for a teacher) irrelevant. This may have wider implications for those changing schools, given the apparent close alignment with school, rather than individual priorities. If this is the experience for many teachers, there is a potential gap within the five-year cycle of the PU process that will have to be addressed. 
Common themes from participant' perceptions of the PU process emerged, regardless of whether the teachers had direct experience of it. The most significant was that PU was a bureaucratic task related to monitoring and competence. The teachers overwhelmingly regarded PU as a record-keeping task; for all, this was an administrative burden. However, some also viewed it as helping them to reflect more deeply about their learning. There seemed to be a lack of concern about the implications of the five yearly cycle although one teacher did indicate that a midway 'check-up' would be valuable. Indeed, feedback from PU pilot evaluations indicated that head teachers thought five years would be too long to wait if there were competency issues (Watson and Fox, 2015).

At this stage in the process of PU implementation it is perhaps too early for teachers to be overly concerned about the implications of not being 'signed off', if indeed this is a realistic concern where competence is not an issue. The link between the annual PRD and five year PU meeting may become more apparent as teachers move through the process. However, if some of the experiences of the teachers in this project are replicated around the country, reliance on the quality of line managers undertaking these meetings could undermine the process. Also, there will be particular challenges where there are personnel changes (Watson and Fox, 2015). Furthermore, it is also unclear what the criteria would be for not signing off a teacher. The key principles of PU indicate an entitlement to a system of supportive professional review and development (GTCS, 2014b). However, there are questions as to who makes the decision if a PRD has been supportive and is of good quality. Again, teacher accountability is embedded within a process that is dependent on external, local factors.

It is notable that the interviewees made no mention of any issues around evidencing the impact of learning, a concern highlighted in initial evaluations of the PU pilots (GTCS, 2015). The teachers interviewed were comfortable with the idea of measuring impact through self-evaluation with supporting evidence from line managers, children's work and classroom observations. In addition, there was perhaps more emphasis placed on evidence for those who took part in the PU pilot. 
Self-evaluation is a key area of discussion in PRD meetings but could also be contentious. If PU is understood to be about competency and accountability, there may be limits as to what and how teachers self-evaluate. Self-evaluation as a process of validation is disputed, as noted by the OECD (Watson and Fox, 2015). Watson and Fox ask, '[if] validation is to ensure equitable outcomes then what is the status of self-evaluation in this process if, as the $\operatorname{OECD}(2013,17)$ makes clear, 'selfevaluation is not a valid evaluation for summative purposes?' (p.142). Thus, increasing demands to evidence impact may ensue, which potentially could limit what and how teachers learn; the choice may be to focus on areas that are easily measurable but have short term impact. It may be too early for some of these issues to be apparent.

\section{Conclusion and Recommendations}

PL policies in Scotland adopt two conflicting stances. First, GTCS support materials seem to reflect research evidence around effective PL with collaborative working and enquiry as key features. This is supported by the SCLPL, which has aspirations for teachers to be critically and reflective, engaging in enquiry and creative practices. However, supporting policies, such as PU, indicate a bureaucratic, task-oriented perspective concerned with individual accountability and compliance with set procedures. Participants' experiences here suggest that school context and, by definition school culture and leadership, are crucial factors in both the effectiveness of PL experiences and the enactment of policy.

In addition, Scottish LAs have significant influence on school governance; they are key drivers in the content and format of teacher PL (Ledingham, 2013). For some participants this created tensions as it was sometimes difficult to implement change following these initiatives. This has implications for PL policy requirements, as teachers are individually accountable for their own learning. For example, if teachers are having difficulty implementing new practices within their context, as part of the PU process they have to engage in dialogue with school leaders who, for whatever reason, may be inhibiting or obstructing the process of change by not providing supportive systems. Moreover, the individual nature of PL policy seems to be at odds with research around the effectiveness of collaborative working. It seems that PL has 
to sit within other policies at all levels in education. As Opfer \& Pedder (2011: 379) point out:

In the context of current research on professional development and teacher learning, misunderstanding the nature of teacher learning by underplaying the complexity of the problem leads to focus on the micro context (individual teachers or individual activities or programs) to the exclusion of influences from meso (institutional) and macro (school system) contexts.

Here, it is worth noting a view of the policy process that examines the interplay between macro, meso and micro elements. Author (2016) identifies ways in which policy is framed by international and national political Big-D/Discourses (Gee, 2012), explained by policy mandate and missive, but formed at the local level through little$\mathrm{d} /$ discourse (Gee, 2012). For him, policy is positioned by those who engage in discursive moments when trying to understand policy framing and policy explaining. Deploying positioning theory (Harré, 2004), Author argues for a policy perspective that specifically engages with teacher agency: here, policy is formed by participants during conversational moments.

The research here reported suggests that local context and actors therein play important roles in the delineation of PL, PRD and PU. It would seem then, propitious to examine how individual positioning (the rights duties and obligations individuals are offered and can take up, resist or amend during conversations) might help to understand the interplay between these matters and national/local policy. It is clear, here at least, that changes in whole school systems and the positions of personnel so located, affect the quality of PL experiences, including engagement with learning as well as other requirements such as PRD and PU. What is not yet clear are possible tensions between the individual accountability the PU process places on teachers and the impact of this on collaborative and collective responsibility. Such aspects may only now be coming to fruition. More research, rather than evaluation studies from the GTCS, are needed in order to fully measure the impact of the policy, and 'policy as positioning' (Author, 2016) might offer a way forward here. 
It is also worth noting that the completion of this research comes after significant change proposals in Scottish educational governance. Regional bodies have been established with responsibility for (among other things) PL. There is an emphasis on supporting collaboration at all levels and an aspiration to increase both teacher and school autonomy (Scottish Government, 2017). This might create opportunities to embed more effective systems for professional learning both at school and local level. The challenge will be to create genuine teacher led work that meets local needs rather than compliance to another even less localised body. The role of PU may also change in light of recent policy shifts. There could then, be a shift in the original intention of PU as it becomes subsumed into other policies.

It must be noted though, that this was a small-scale study focusing on the experience of seven primary school teachers. While their experiences of $\mathrm{PL}$, gathered through semi-structured interviews closely aligned with previous research findings, the project was limited in scope. The data set was small (exclusively class committed primary school teachers). There is a need therefore, to examine the experiences of a larger number of Scottish teachers to determine if the professional views in this project are generalisable to a wider population. However, the project raises a number of issues for exploration including comparisons between different teachers working in different contexts and sectors, and those who are at different stages in their careers. Possible areas to be addressed include:

- Do perceptions and experiences of PL change at different career stages?

- Are there particular issues/tensions for specific groups of teachers, e.g. those working on temporary contracts or those who change roles/schools within the five-year PU cycle?

- What are the issues for those charged with leading PL policy at school level?

- How has PU contributed to the wider aims of educational reform?

- How have the original aims of PU changed since its first inception and what is the impact of such change?

- Does the heuristic 'policy as positioning' (Author, 2016) offer a lens through which to examine Scottish PL? 
The changes to PL policy including the first cycle of PU are nested within wider system changes, such as the National Improvement Framework, aimed at closing the attainment gap as well as system changes to school governance. The experiences of teacher PL is an under researched area in Scotland and yet with growing rhetoric emphasising teacher quality and aligning this with the attainment agenda and competency there is a need for this area to be explored further.

\section{References}

Alexander, R. (Ed.). (2010). Children, their World, their Education: Final report and recommendations of the Cambridge Primary Review. Oxon, England: Routledge.

Armour, K., Makopoulou, K. and Chambers, F. (2012) Progression in physical education teachers' career-long professional learning: Conceptual and practical concerns. European Physical Education Review, 18(1) 62-77.

Braun, V. and Clark, V. (2006). Using thematic analysis in psychology. Qualitative Research in Psychology, 3 (2), 77-101.

Coe, R., Aloisi, C., Higgins, S. \& Major, L, E. (2014). What Makes Great Teaching. The Sutton Trust. Retrieved $13^{\text {th }}$ February 2015 from

\section{http://www.suttontrust.com/researcharchive/great-teaching/}

Cohen, L, Manion, L. \& Morrison, K. (2007). Research Methods in Education. Oxford: Routledge

Collin, S., Karsenti, T. and Komis, V. (2013). Reflective practice in initial teacher training: critiques and perspectives in reflective practice: International and Multidisciplinary Perspectives. 14:1 104-117.

Day, C., and Sachs, J. (2004). International Handbook on the Continuing Professional Development of Teachers. Maidenhead: Open University Press

Donaldson, G. (2011). Teaching Scotland's Future - report of a review of teacher education in Scotland. Retrieved from http://www.scotland.gov.uk/Publications/2011/01/13092132/0

Education Council New Zealand (2017) Code of Professional Responsibility and Standards for the Teaching Profession. Wellington: New Zealand Eraut, M. (1994). Developing Professional Knowledge and Competence. Bristol: The Falmer Press. 
Forde, C., McMahon, M. A., Hamilton, G., Murray R. (2016). Rethinking professional standards to promote professional learning. Professional Development in Education. 42:1. 19-35.

Grek, S., Lawn, M., Lingard, B., Ozga, J., Rinne, R., Segerholm, C., Simola, H. (2009) National policy brokering and the construction of the European Education Space in England, Sweden, Finland and Scotland. Comparative Education 45: 1, $5-21$.

GTCS (2012a). Code of Professionalism and Conduct. Retrieved from http://www.gtcs.org.uk/web/FILES/teacher-regulation/copac-0412.pdf

GTCS (2012b). Standard for Career Long Professional Learning. Retrieved from http://www.gtcs.org.uk/professional-standards/the-standards/standard-for-careerlong-professional-learning.aspx

GTCS (2014a) Professional Update Guidance Notes. Retrieved from http://www.gtcs.org.uk/professional-update/professional-learning/professionallearning-journey-using-evidence-of-impact.aspx

GTCS (2014b). Professional Update: What does it mean in practice? Teaching in Scotland. Issue 57: 18-22. Retrieved from http://www.gtcs.org.uk/web/FILES/teaching-scotland/teaching-scotland-issue57.pdf

GTCS (2015). Professional Update Pilot Phase 2 Evaluation. Retrieved from http://www.gtcs.org.uk/web/FILES/professional-development/pupp2fe.pdf.

Harland, J. and Kinder, K. (1997) Teachers' continuing professional development: framing a model of outcomes, British Journal of In-service Education, 23:1, 7184.

Harré, R. (2004). Positioning Theory. Retrieved from www. massey.ac.nz/ alock/virtual/positioning.doc,

Hatton, N. and Smith, D. (1995). Reflection in teacher education: Toward definition and implementation. Teaching and Teacher Education 11:1, 33-49.

Hepburn, H. (2015). 'Tick-box approach threatens future of Professional Update' Times Educational Supplement Scotland. 19th June 2015, p.10.

Humes, W. (2014). Professional update and practitioner enquiry: Old wine in new bottles? Scottish Educational Review. 48 (2). 54-72. 
King, F. (2014). Evaluating the impact of teacher professional development: an evidence based framework, Professional Development in Education, 40:1, 8911.

Ledingham, D. (2013). The Local governance of Education. Bryce T.G.K., Humes, W., Gillies, D. and Kennedy A. Scottish Education Referendum Fourth Edition pp 174-184). Edinburgh: Edinburgh University Press.

McCormac, G. (2011). Advancing Teacher Professionalism: The report of the review of teacher employment in Scotland. Retrieved from http://www.gov.scot/Resource/Doc/920/0120902.pdf.

Miles, M. \& Huberman, M (1994). Qualitative Data Analysis: An Expanded Sourcebook. London: Sage.

OECD (2005). Teachers Matter: Attracting, Developing and Retaining Effective Teachers. Retrieved from http://www.oecd.org/education/school/34990905.pdf. O'Brien, J (2011). Continuing Professional development of Scottish teachers: tensions in policy and practice. Professional Development in Education, 37: 5, 777-792.

Opfer, V.D. and Pedder, D. (2011) Conceptualizing Teacher Professional Learning. Review of Educational Research. 81:3 376-407.

Punch, K. (2014). Research Methods in Education. London: Sage.

Rahman, A., Hoban, G. and Neilsen, W. (2014). Transcending teacher professional development: From determinism to complexity. Presented at the Asian Conference on Education. Nagoya, Japan. Retrieved from http://ro.uow.edu.au/sspapers/1495/

Richards, L. (2009). Handling Qualitative Data (2 ${ }^{\text {nd }}$ Edn.). London: Sage

Robson, C (2002). Real World Research ( $3^{\text {rd }}$ Ed). Real World Research. Oxford: Wiley.

Schon, D. (1983). The Reflective Practitioner: How professionals think in action. New York: Basic Books.

Scottish Executive (2001). A Teaching Profession for the $21^{\text {st }}$ Century. Retrieved from http://www.gov.scot/Publications/2001/01/7959/File-1

Scottish Government. (2011). Continuing to Build Excellence in Teaching. The Scottish Government's Response to Teaching Scotland's Future. Retrieved from http://www.gov.scot/Resource/Doc/920/0114570.pdf. 
Scottish Government (2019). 2019 National Improvement Framework and Improvement Plan. Retrieved from https://www.gov.scot/publications/2019national-improvement-framework-improvement-plan/

Scottish Government. (2017). Education Governance: Next Steps. Empowering our teachers, parents and communities to deliver excellence and equity for our children. Retrieved from http://www.gov.scot/Resource/0052/00521038.pdf

Sheurich, J. J. (1995). A post-modernist critique of research interviewing. Qualitative Studies in Education, 8 (3) 239-252.

Silverman, D. (2006). Interpreting Qualitative Data. London: Sage.

Sugrue, C. (2011). Irish teachers experience of professional development: performative or transformative. Professional Development in Teacher Education: European Perspectives. 37:5 793-815.

Teaching Council of Ireland (2011) Draft Policy Paper on the Continuum of Teacher Education.

Teaching Council of Ireland (2016) Cosán: Framework for Teachers' Learning. Maynooth: The Teaching Council of Ireland

.Timperley, H. (2008). Teacher professional learning and development. Educational Practices. 18:1-31.

Tuinamuana, K. (2011). Teacher Professional Standards, Accountability and Ideology: Alternative discourses. Australian Journal of Teacher Education, 36 : 12 pp 72-82.

Watson, C. and Fox, A. (2015). Professional re-accreditation: constructing educational policy for career-long teacher professional learning. Journal of Education Policy 30:1,132-144. 